\title{
Do Neighborhoods Matter Differently for Movers and Non-Movers?: Analysis of Weight Gain in the Longitudinal Dallas Heart Study
}

\begin{abstract}
The few available population-based longitudinal studies examining the link between change in neighborhood condition and weight change to date have only examined neighborhood changes generated by residential mobility. Applying a difference-in-difference analytic framework to data from the Dallas Heart Study (DHS), a multi-ethnic, population-based cohort in Dallas County, TX, we evaluated the relationship between changes in neighborhood condition and weight change for both movers and non-movers over an approximate seven-year follow-up period. We employed a novel measure of neighborhood condition based on property appraisal data to capture temporally consistent measures of change in neighborhood condition regardless of residential mobility. We observed an inverse relationship between weight change and change in neighborhood condition which was more pronounced for non-movers ( 1.9 fewer kilograms gained per 1-standard deviation improvement in neighborhood condition) than for movers (1.5 fewer kilograms gained per 1-standard deviation improvement in neighborhood condition).
\end{abstract}

SUPPORT: This work was supported in part by a grant from the National Science Foundation (NSF/SES-0827350). Funding support for Dr. Powell-Wiley is provided by the Division of Intramural Research of the National Heart, Lung, and Blood Institute (NHLBI) at the National Institutes of Health (NIH). Funding support for Mr. Ayers is provided through a professional services contract (contract \#HHSN268201300173P) through the Division of Intramural Research of NHLBI at NIH. Funding support for Dr. Neeland is provided by grant 1K23DK106520 from the National Institute of Diabetes and Digestive and Kidney Diseases of the National Institute of Health and by the Dedman Family Scholarship in Clinical Care from UT Southwestern. The views expressed in this manuscript are those of the authors and do not necessarily represent the views of the National Heart, Lung, and Blood Institute; the National Institutes of Health; or the U.S. Department of Health and Human Services.

ACKNOWLEDGEMENTS: We are thankful for the GIS analytic support of Wenyuan Yin. 


\section{INTRODUCTION}

Excess adiposity has been robustly associated with numerous deleterious health outcomes including increased risk of incident cardiovascular disease, certain types of cancer, and all-cause mortality. ${ }^{1-5}$ Additionally, adverse neighborhood environment conditions, specifically as measured by neighborhood-level socioeconomic status or neighborhood physical environment, have been associated with prevalent obesity and weight gain, contributing to increased cardiometabolic risk over time ${ }^{6-11}$. However, population-based longitudinal studies examining the link between changes in neighborhood condition and weight change are rare, with prior work limited to evaluating changes in particular aspects of the physical environment ${ }^{12}$ or these neighborhood changes' impact on specific populations ${ }^{13}$. Furthermore, existing longitudinal studies have several shortcomings including lack of objectively measured weight change ${ }^{14,15}$, small sample sizes or limited numbers of participants with measurable change in neighborhood environments $^{1,16}$ and lack of a population-based sample. ${ }^{17}$

The question of how to best measure changes in neighborhood condition, or changes in the quality of the physical neighborhood environment, is a challenge. Prior studies have often relied on Census data and have, unfortunately, been limited by Census geographies and the time periods over which Census data is reported. Additionally, studies have depended on commercially available data characterizing the physical environment, where data utilization may be constrained by $\operatorname{cost}^{12,13}$. To address these shortcomings of previous neighborhood condition measures, we have utilized a novel measure of neighborhood condition derived from residential housing appraisal data which is publicly available at little or no cost. ${ }^{18}$ The appraisal-based measure of neighborhood condition allowed for more consistent temporal and geographic correspondence of neighborhood change and weight change.

\section{Neighborhood Change and Weight Gain for Movers and Non-movers}

Another important question to consider is whether weight gain is differentially affected by moving to a new neighborhood or remaining in the same neighborhood which evolves over time. Change in neighborhood conditions can be experienced for non-movers by longitudinal differences in an existing neighborhood over time or, for movers, by differences between neighborhoods. It is unknown whether differences in neighborhood conditions experienced by these two mechanisms are associated with similar effects on resident weight change. Existing studies have examined the relationship between neighborhoods and weight change by examining residents who moved to new neighborhoods. ${ }^{19,20}$ However, it is unknown how neighborhoods affect residents who remained in the neighborhood as the neighborhood condition changed. This relationship, in particular, is challenging to measure because of the relatively long follow-up period needed to measure neighborhood change with Census-derived measures due to the timeaveraging of American Community Survey data. ${ }^{21}$

Using longitudinal data from the Dallas Heart Study (DHS), a multi-ethnic, population-based cohort in Dallas County, TX, we evaluated the relationship between relative changes in neighborhood condition between 2000 and 2009 and weight change for study participantsincluding both movers and non-movers. In particular, we examined differences in the relationship between relative change in neighborhood condition and weight change for both movers and non-movers. Examining heterogeneity in the effects of neighborhood for different 
types of people has implications for both place-based interventions targeting the built environment and individual-level interventions targeting chronic disease prevention.

The primary aim of our study is to examine the relationship between changes in a novel, appraisal-based measure of neighborhood condition and weight gain. While a causal mechanism for why neighborhood condition change is related to weight change has not been robustly established, leading theories suggest that associations between neighborhood walkability ${ }^{22}$ and neighborhood crime ${ }^{23}$ and physical activity levels alongside personal preferences for these neighborhood characteristics are important. The appraisal-based measure of neighborhood provides a relative composite measure of neighborhood walkability, crime and other neighborhood features weighted by the degree to which residents prefer these neighborhood features. We expect that these neighborhood features impact the behavior of movers and nonmovers similarly, but no evidence currently exists to test this hypothesis. The present study will test two hypotheses. First, based upon previous findings ${ }^{6,7}$, we hypothesize that improved neighborhoods will be associated with less weight gain. Second, we expect that the effects will be similar for both movers and non-movers.

\section{METHODS}

\section{Sample}

The DHS enrolled a probability-based population sample of Dallas County, TX residents, aged 18-65 at study entry. Original data collection including detailed surveys, anthropometric measures, and laboratory testing, was conducted at baseline in 2000-2002, with follow-up data collected in 2007-2009. Data collection details have been previously reported. ${ }^{24}$ The DHS protocol was approved by the University of Texas Southwestern Medical Center's IRB, and written informed consent was obtained from participants at study entry and follow-up. A protocol to analyze DHS neighborhood data (13-H-N041) was approved by NHLBI's IRB.

In total, 2,485 participants participated in both initial and follow-up DHS data collection. Of these participants, those who moved out of Dallas County $(n=461)$; those who lived in areas without reliable house appraisal values $(n=147)$; those that had missing/inadequate address data $(n=1)$; those that had missing neighborhood perception data $(n=435)$; those who reported race/ethnicity other than black, white, or Hispanic $(n=33)$; those that had missing height or weight data $(n=11)$; participants who had a cancer history $(n=114)$, bariatric surgery history $(n=22)$, and who were pregnant at baseline or follow-up $(n=8)$ were excluded. The final analysis sample consisted of 1,253 participants.

\section{Measures}

\section{Participant's individual characteristics}

Demographic medical history data including age, gender, race/ethnicity, income, education, address, and smoking status was measured via self-report at study entry and follow-up. Participants were characterized as "movers" or "non-movers" based upon a comparison of the two reported residential addresses; change in address was considered as moving. Physical activity measured at baseline and follow-up was determined from self-reported leisure-time 
physical activity to which a validated conversion scale for activity intensity was applied to compute metabolic equivalents (METs)-minutes per week. ${ }^{25-27}$ Height and weight were measured at both time points to calculate body mass index (BMI) in kilograms per meter-squared.

\section{Neighborhood perceptions and housing condition}

At both baseline and follow-up, participants also responded to 18 survey questions regarding perceptions of their neighborhood environment; questions were abstracted from the 1994 Project on Human Development in Chicago Neighborhoods. ${ }^{28}$ Three separate measures of neighborhood perceptions were derived from these questions: physical environment (Cronbach's $\alpha-$ coefficient $=0.82$ ), neighborhood violence (Cronbach's $\alpha$ coefficient $=0.84$ ), and social cohesion (Cronbach's $\alpha$-coefficient $=0.76$ ). In all cases, a higher score was indicative of more unfavorable perceptions about one's neighborhood.

Objectively measured neighborhood housing condition data was obtained from the Dallas Central Appraisal District for 2000 and 2009 and matched to baseline and follow-up survey data, respectively. The appraisal district annually rates each residential property's overall condition according to an eight-point scale ranging from unsound (1) to excellent (8). The conditions of all properties within a half-mile radius of each DHS participant's home were averaged to create a measure of average neighborhood housing condition.

\section{Appraisal based measure of neighborhood}

Residential property appraisal data was used to derive a measure of neighborhood condition that is based upon the average local homebuyer's evaluation of the quality of the built and social neighborhood environment. Our measure of neighborhood condition is based upon hedonic price theory applied to residential housing markets. ${ }^{29-32}$ Hedonic price theory explains how a home's price can be decomposed into individual prices for each of the varied characteristics of the home (e.g., number of bedrooms, existence of central air, type of foundation, school district, etc), including neighborhood condition. ${ }^{32,33}$ We used this theory to develop our measure of neighborhood condition. Full details and analysis of the validity of this measure are reported elsewhere. $^{18}$

The neighborhood condition measure was constructed using appraisal and property characteristic data for all single family residence properties in Dallas County, TX. Data were obtained from the Dallas Central Appraisal District's 2000 and 2009 certified property appraisal data files. ${ }^{34}$ First, the data were used to estimate a hedonic regression model to control for non-neighborhood characteristics of the housing bundle. The dependent variable was the natural log of the property appraisal value. Independent variables included the following housing characteristics: indicator variables for school district and city jurisdiction in which the property is located, house age and age squared, condition of the house structure as assessed by the appraisal district using an eightpoint scale ranging from unsound to excellent, square feet of living area, number of stories, type of foundation (e.g. slab, pier and beam, post, or block), type of fence (e.g. stone, wood, iron, brick, chain, none), presence of central air conditioning, number of fireplaces, number of bathrooms and presence of a swimming pool. Neighborhood condition was calculated as the difference between the actual appraisal value and the value predicted from the estimated hedonic regression equation for each single family residence. Values of neighborhood condition for each 
single family residence were then standardized so that a value of 1 corresponded to neighborhood condition that was one-standard deviation above the county-mean neighborhood condition. All values for neighborhood condition within a half-mile buffer around each DHS participant's home address were then averaged to obtain the standardized neighborhood condition measure. Thus, the measure of neighborhood indicated in relative terms how desirable a neighborhood was compared to the average neighborhood in Dallas County. Neighborhood features that constituted a desirable neighborhood were those elements of a neighborhood that homebuyers on average preferred (and thus were willing to pay more for) when purchasing a new home.

\section{Analysis}

Multilevel linear regression models with block group random effects were estimated to examine the relationship between change in standardized neighborhood condition and weight change using a difference-in-difference strategy. ${ }^{35}$

$y_{i t}=X_{i t} \beta+\alpha$ FollowUP $_{t}+\gamma$ NeighborhoodChange $_{i}+\delta$ FollowU $_{t} \times$ NeighborhoodChange $_{i}+$ $\epsilon_{i t} \quad(1)$

Each participant's $(i)$ weight $\left(y_{i t}\right)$ was observed at 2 time points ( $\left.\mathrm{t}\right)$ - baseline $(t=1)$ and followup $(t=2)$. $X$ is a vector of individual characteristics (age, age squared, gender, race/ethnicity, smoking, income, education, physical activity, mover status, and Heckman correction factor (described below)). Models included several key covaraites necessary for implementing the difference-in-difference model. FOLLOW-UP was an indicator variable for observations from follow-up. Neighborhood Change was the change in standardized neighborhood condition from 2000 (corresponding to baseline) to 2009 (corresponding to follow-up) and is our measure of treatment. Participants whose neighborhood did not change (in relative terms) between 2000 and 2009 will have a value of 0 for Neighborhood Change and may be considered the control group. A value of 1 for Neighborhood Change indicates a neighborhood which improved it's relative position in the distribution of Dallas County neighborhoods by 1 standard deviation. The estimated coefficient associated with interaction of Neighborhood Change and FOLLOW-UP $(\delta)$ measures the change in weight expected from a 1 standard deviation change in relative neighborhood condition from baseline to follow-up.

The difference-in-difference strategy allowed us to compare weight change over time among DHS participants who experienced a change in neighborhood condition (the "treated" group) to weight change over time among DHS participants whose neighborhood condition did not change (the "control" group). Under the assumption that weight change would have been the same in treatment and control groups had there been no neighborhood change, estimates of $\delta$ identify the weight change associated with change in neighborhood condition. Models were estimated for the entire sample and stratified by mover/non-mover status.

\section{Heckman correction factor}

Analysis of the effects of neighborhoods on individual outcomes has distinct challenges when analyzing mobile and non-mobile populations. For the case of mobile populations (e.g., movers), one must contend with the element of choice. To the extent that individuals may have 
chosen the neighborhood to which they relocated, the choice of neighborhood is confounded with the change in neighborhood condition. For the case of non-mobile populations, confounding occurs in a different sense: non-mobile neighborhood residents could have, to varying degrees, affected their neighborhood's condition through individual or community efforts. $^{36}$ In both cases, the challenge is one of self-selection: to varying degrees, neighborhood residents may have "self-selected" into the type of neighborhood change they received. In the analysis described below, we have relied on the Heckman Correction Factor (HCF) to account for self-selection into neighborhoods that improved or worsened. The HCF has been shown to provide reliable causal estimates in the presence of self-selection. ${ }^{37}$ The HCF explicitly modeled the likelihood of self-selection into an improved neighborhood in a first stage probit regression. The dependent variable was an indicator for observations in which Neighborhood Change was greater than 0 and covariates included age, sex, race, education, household income, physical activity, total years in Dallas County neighborhood at baseline, home ownership, employment status, marital status, and number of children. The predicted probability was then included as an additional control in the second stage regression analysis. Additional robustness checks were conducted modeling the HCF as selection into varying degrees of improved or worsening neighborhoods.

\section{Propensity Scoring}

Propensity scoring was used to account for non-random assignment of mover/non-mover status.

38 A propensity score for moving was generated from a probit model, adjusting for age, gender, race/ethnicity, education, income, exercise, tenure in neighborhood, home ownership status, marital status, employment, number of kids, and change in BMI. A mover was matched to a nonmover via a greedy algorithm, in which the algorithm made "best" matches first and "next-best" matches next, in a hierarchical sequence until no more matches could be made. ${ }^{39}$ Best matches were those with the highest digit match on propensity score using Euclidean distances. A bound of \pm 0.05 for the propensity score was reported, but additional robustness checks were conducted varying the matching criteria of the distance from 0.005 to 0.200 in increments of 0.005 .

\section{RESULTS}

Summary statistics for the full analysis sample at both baseline and follow-up are reported in Table $1.42 \%$ of participants were male; $53 \%$ were non-Hispanic black and $17 \%$ were Hispanic. Over the approximate 7-year follow-up period, mean weight of the DHS cohort increased by 2.8 kilograms. Based upon BMI, participants were primarily overweight (33\%) or obese (42\%) at baseline. By follow-up the proportion obese had risen to $52 \%$. Weight gain in this study appears to be occurring among the overweight/obese population rather than among under weight individuals. Approximately a quarter of the sample were self-reported current smokers; over $50 \%$ had some college education; and income was fairly evenly distributed among the various categories with $69 \%$ earning less than $\$ 50,000$ per year. Smoking status, education, income, neighborhood house condition, and perceptions of neighborhood violence and social cohesion remained relatively constant across sample periods. On average, participants reported worse perceptions of the physical neighborhood environment at baseline than at follow up.

There were several statistically significant differences in the mean characteristics of the mover and non-mover sub-groups [Table 2]. On average, non-movers were older, more likely to be 
white males, less physically active (only at baseline), less likely to smoke, had more education and higher incomes than movers. Also, non-movers reported more favorable perceptions of their present neighborhood than movers at both baseline and follow-up. However, the average neighborhood house condition in non-mover neighborhoods was worse at baseline, but better at follow-up. Further, on average, mover's neighborhoods worsened over the 7-year study window, while non-mover's neighborhoods remained the same.

\section{Neighborhood change and weight change, full sample}

First, we estimated difference-in-difference models to assess the relationship between a 1-unit change in standardized neighborhood condition and weight change [Table 3]. Model 1 was the base specification and controlled for individual socio-demographic characteristics, mover status, and the Heckman Correction factor to account for self-selection into neighborhoods. Model estimates indicated no statistically significant relationship between change in neighborhood condition and weight gain. Models 2 and 3 incrementally included additional controls for the condition of neighborhood housing structures and neighborhood perceptions, respectively.

When the condition of neighborhood housing structures was accounted for, the relationship between change in neighborhood condition and weight change became statistically significant. A 1 standard deviation improvement in neighborhood condition was related to 0.7 fewer kilograms gained. Thus, for example, if a neighborhood that was in the bottom of the distribution of neighborhoods (specifically, 1 standard deviation below the mean) improved and became an average neighborhood, then the model estimated that residents could expect to gain 0.7 fewer kilograms. This relationship remained $(\mathrm{p}=0.06)$ when neighborhood perceptions were incorporated into the model.

Regarding socio-demographic characteristics, older individuals, males, African Americans, and those who are less physically active had higher weight. Likewise, current smokers weighed less. The estimated association between weight and age was non-linear: older age was associated with higher weight up to age 52, after which the relationship reversed. The Heckman correction factor was also statistically significant across all three models, emphasizing the importance of accounting for neighborhood selection; individuals more likely to select into improved neighborhoods had less weight gain than those who did not.

\section{Stratified Analysis: Movers and Non-Movers}

A Chow test ${ }^{40}$ of equality between regression parameters across mover and non-mover subgroups resulted in rejection of the null hypothesis of equality $(\mathrm{p}=0.021)$, indicating a need for stratified analysis. Stratified analysis for both the full, stratified sample and the propensitymatched samples are presented in Table 4. Estimation results for the full, stratified sample are presented first; they indicate that neighborhood change was related to weight change only among non-movers. For the propensity-matched samples, however, the relationship between neighborhood change and weight change was significant across both sub-groups. Point estimates indicate that a 1 standard deviation improvement in neighborhood condition was associated with 1.5 and 1.9 fewer kilograms gained for movers and non-movers, respectively. These two effect size estimates were statistically distinguishable $(\mathrm{p}<0.0001)$. 


\section{Sensitivity analysis}

Additional robustness checks were conducted to test the sensitivity of results to (1) specification of the HCF and (2) specification of the propensity-scoring model. Results were insensitive to variations in both specifications (data not shown).

\section{DISCUSSION}

We have demonstrated that an improvement in neighborhood condition is associated with less weight gain over time, even after controlling for self-selection into neighborhoods and mover/non-mover status. This relationship between weight change and change in neighborhood condition was more pronounced for non-movers (1.9 fewer kilograms gained per 1-standard deviation improvement in neighborhood condition) than for movers (1.5 fewer kilograms gained per 1-standard deviation improvement in neighborhood condition). Non-movers may be more strongly impacted by their neighborhood due to longer residence in the neighborhood. Nonmovers may spend a larger proportion of their time close to the neighborhood, while movers may utilize some services, institutions or businesses closer to their previous neighborhood. Although causality cannot be proven, our findings support the hypothesis that improvements in neighborhood condition can reduce weight gain over time, particularly for long-term neighborhood residents. While a 1.9-kilogram reduction in weight at the individual-level is of unclear clinical relevance, population-level reductions in weight gain of this magnitude can have important implications on the cardiometabolic health of society. ${ }^{41}$

This study is the first to empirically examine the longitudinal relationship between weight change and our measure of neighborhood condition utilizing residuals from a hedonic price regression. This appraisal-based measure of neighborhood condition has allowed us to overcome several notable limitations associated with the use of Census-derived measures of neighborhood condition. First, we have been able to define neighborhood condition based on a buffer around the participant's home rather than using Census geography; thus, mitigating edge effects. ${ }^{42}$ Second, the measure of neighborhood condition was temporally consistent with the measurement of weight since appraisal data were available annually. While US Census data available from the American Community Survey provides 3- and 5-year estimates of various indicators of neighborhood SES, these data are derived from samples taken over multiple years. Thus they fall short of providing a temporally matched measure of neighborhood quality and are likely to under estimate changes over relatively short time periods due the averaging of data from multiple years. Third, the measure we derived from appraisal data were based upon robust work by economists and had a well-established theoretically consistent basis. ${ }^{29-32}$

This study is also the first to compare the longitudinal relationship between change in neighborhood and weight change among a mover and non-mover population. Although this question has not been answered directly, these results are consistent with previous work in the field. Prior work has estimated associations between neighborhood condition and BMI among a mixed (mover/non-mover sample). ${ }^{12}$ Other literature has reported that among movers in the DHS, participants who moved to a neighborhood of lower deprivation (defined using Census measures) experienced less weight gain ${ }^{20}$. Neighborhood deprivation among non-movers in DHS was also correlated with weight gain. ${ }^{11}$ Additionally, the Moving-To-Opportunity Study, which randomized individuals to areas of varying neighborhood socio-economic status, provided 
suggestive evidence that moving from a high poverty census tract to a low poverty census tract was associated with a lower likelihood of morbid obesity but noted that the mechanism driving this association was unknown. ${ }^{19}$ As we have seen in our prior work, perceptions of neighborhood environment as a measure of psychosocial stress does not appear to explain the relationship between change in neighborhood condition and weight change. ${ }^{20,43}$

Other authors have also examined the relationship between health outcomes and housing appraisal data. ${ }^{44-47}$ Our results are substantively similar: poorer health outcomes are more likely in neighborhoods with generally lower appraisal values. However, our application of hedonic theory to derive a theoretically-grounded measure from neighborhood appraisals and our application of the measure to longitudinal data provide the most robust result to date to demonstrate poorer health outcomes are more likely in neighborhoods with generally lower appraisal values. Previous work has found that neighborhood appraisal values are correlated with self-reported perceptions characterizing obesogenic environments and attenuated the relationship between perceptions of the neighborhood environment and BMI in cross-sectional analysis. ${ }^{45}$ However, it was not clear if this relationship was due to variations in neighborhood condition reflected in appraisal data, or some other confounder. Our use of a hedonic regression to extract a measure of neighborhood condition from appraisal data helps to rule out many potential confounders that may have been driving the previously estimated relationships. Further, our results illustrate that in longitudinal analysis, neighborhood condition impacts health independent of housing conditions - a finding not evident in previous applications of appraisal data.

While statistically significant correlations between neighborhood socioeconomic level and weight change have been previously reported in longitudinal studies, the causal mechanism between neighborhoods and residents' weight change remains largely unknown. 19,20 Studies have suggested mechanisms such as varying degrees of neighborhood safety ${ }^{48}$, neighborhood walkability ${ }^{22,49}$, commuting times that differ with distance to employment centers 50,51 , peer effects 52,53 , and various other elements of the built environment 54,55 . Our measure of neighborhood condition has the potential to provide additional insight into the mechanisms through which neighborhoods affect residents' weight gain. Neighborhood change was not significantly related to weight change until neighborhood housing condition was added as a control. Controlling for neighborhood housing condition caused the estimated association between neighborhood change and weight gain to increase (in absolute value). This suggests that change in neighborhood condition, independent of the quality and condition of housing structures, is important in the causal pathway linking neighborhoods and weight gain. Additionally, only those elements of neighborhood SES that affect potential home buyer's "offer" price when bidding on a new home contribute to our measure of neighborhood condition. Thus, aspects of SES used to proxy neighborhood condition in Census-derived measures such as median neighborhood income or average education levels are likely not included in our measure of neighborhood condition because they are generally not known to potential homebuyers; while features of the built environment such as presence of parks, ${ }^{56}$ neighborhood aesthetics and physical disorder, ${ }^{57}$ and in some cases racial composition ${ }^{58}$ are potentially included in our measure of neighborhood condition. Additionally, our measure of neighborhood condition varies over very small geographic scales and on an 
annual basis. For example, in Dallas County, TX (the location of the present study), the presence of a foreclosed property and the associated neighborhood blight is measured by our measure of neighborhood condition, but only for homes which lie within 250 feet of the foreclosed property, and only for up to 12 months following a foreclosure auction..$^{59-61}$ Any aspect of neighborhood condition that affects home prices will produce variations in our measure of neighborhood condition.

Limitations of the present study include reliance on a population-based sample from a single geographic area. The external validity of these results to other metropolitan areas is unknown. Additionally, this study utilized a validated, but self-reported measure of physical activity and lacked information on dietary intake. It is possible that confounders exist that were not included in the hedonic regression used to derive our measure of neighborhood condition. Further discussion of the limitations of our neighborhood condition measure may be found in the literature. ${ }^{18}$ Also, our study does not have information on when participants moved between base-line and follow-up; this may downward bias the relationship between neighborhoods and weight gain for non-movers. Finally, although for many low-income populations, the choice set for residential location and the decision to move is extremely limited due to inability to pay for most options ${ }^{62-}$ 65,DHS participants were free to self-select into neighborhoods and into mover/non-mover status. Effects of potential self-selection, despite our inclusion of the HCF and propensity scoring strategy, is a potential limitation to the causal interpretation of our results.

Nevertheless, our results have important implications for future research. Appraisal data is available at little cost for most large metro areas. Additional studies similar to this one in diverse urban areas will help inform the external validity of our results. Also, future work combining appraisal data and other observational measures of neighborhood across multiple cities is needed to better understand the aspects of neighborhood being measured by appraisal data. We need more information on how appraisal data from different cities measure similar/different aspects of neighborhoods before the methods presented here can be applied to studies spanning a larger geographic area. Study results also highlight the importance of studying the effects of neighborhood change separately for mover and nonmover populations. Careful attention to self-selection associated with moving is needed, but these studies serve to inform how housing policy might impact health. In particular, current housing policy impacts the neighborhoods experienced by low-income families either through moving families from bad neighborhoods to good ones (e.g., Section 8 housing vouchers ${ }^{66}$ ) or through improving neighborhoods for non-movers (e.g., the Neighborhood Stabilization Program ${ }^{67}$ ). Information regarding the heterogeneous impact of these policies is important for optimal implementation with regards to health. 


\section{References}

1. Berrington de Gonzalez A, Hartge P, Cerhan JR, Flint AJ, Hannan L, MacInnis RJ, Moore SC, Tobias GS, Anton-Culver H, Freeman LB. Body-mass index and mortality among 1.46 million white adults. New England Journal of Medicine 2010;363(23):2211-2219.

2. Cohen SS, Park Y, Signorello LB, Patel AV, Boggs DA, Kolonel LN, Kitahara CM, Knutsen SF, Gillanders E, Monroe KR. A Pooled Analysis of Body Mass Index and Mortality among African Americans. 2014.

3. Mozaffarian D, Benjamin EJ, Go AS, Arnett DK, Blaha MJ, Cushman M, de Ferranti S, Despres J-P, Fullerton HJ, Howard VJ. Heart disease and stroke statistics-2015 update: a report from the american heart association. Circulation 2015;131(4):e29.

4. ki Angelantonio E, Bhupathiraju SN, Wormser D, Gao P, Kaptoge S, Berrington de Gonzalez A, Cairns BJ. Body-mass index and all-cause mortality: individualparticipant-data meta-analysis of 239 prospective studies in four continents. The Lancet 2016.

5. Lavie CJ, Milani RV, Ventura HO. Obesity and ardiovascular disease: risk factor, paradox, and impact of weight loss. Journal of the American College of Cardiology 2009;53(21):1925-1932.

6. Black JL, Macinko J. The changing distribution and determinants of obesity in the neighborhoods of New York City, 2003-2007. Am J Epidemiol 2010;171(7):765-75.

7. Corsi DJ, Finlay JE, Subramanian SV. Weight of communities: a multilevel analysis of body mass index in 32,814 neighborhoods in 57 low- to middle-income countries (LMICs). Social science \& medicine 2012;75(2):311-22.

8. Laraia BA, Karter AJ, Warton EM, Schillinger D, Moffet HH, Adler N. Place matters: neighborhood deprivation and cardiometabolic risk factors in the Diabetes Study of Northern California (DISTANCE). Social science \& medicine 2012;74(7):1082-90.

9. Lovasi GS, Neckerman KM, Quinn JW, Weiss CC, Rundle A. Effect of individual or neighborhood disadvantage on the association between neighborhood walkability and body mass index. Am J Public Health 2009;99(2):279-84.

10. Mujahid MS, Diez Roux AV, Borrell LN, Nieto FJ. Cross-sectional and longitudinal associations of BMI with socioeconomic characteristics. Obes Res 2005;13(8):141221.

11. Powell-Wiley TM, Ayers C, Agyemang P, Leonard T, Berrigan D, Ballard-Barbash R, Lian M, Das SR, Hoehner CM. Neighborhood-level socioeconomic deprivation predicts weight gain in a multi-ethnic population: Longitudinal data from the Dallas Heart Study. Preventive medicine 2014;66:22-27.

12. Hirsch JA, Moore KA, Barrientos - Gutierrez T, Brines SJ, Zagorski MA, Rodriguez DA, Diez Roux AV. Built environment change and change in BMI and waist circumference: Multi - ethnic Study of Atherosclerosis. Obesity 2014;22(11):24502457.

13. Michael Y, Nagel C, Gold R, Hillier T. Does change in the neighborhood environment prevent obesity in older women? Social Sci Med 2013;93:176-179.

14. Berry TR, Spence JC, Blanchard CM, Cutumisu N, Edwards J, Selfridge G. A longitudinal and cross-sectional examination of the relationship between reasons 
for choosing a neighbourhood, physical activity and body mass index. Int J Behav Nutr Phys Act 2010;7:57.

15. Inagami S, Cohen DA, Finch BK. Non-residential neighborhood exposures suppress neighborhood effects on self-rated health. Soc Sci Med 2007;65(8):1779-91.

16. Ewing R, Brownson RC, Berrigan D. Relationship between urban sprawl and weight of United States youth. Am J Prev Med 2006;31(6):464-74.

17. Lee IM, Ewing R, Sesso HD. The built environment and physical activity levels: the Harvard Alumni Health Study. Am J Prev Med 2009;37(4):293-8.

18. Leonard T, Powell-Wiley TM, Ayers CR, Yin W, Murdoch JC, Pruitt SL. Property Values as a Measure of Neighborhoods-Assessment of Methodologies and Theoretical Basis. Epidemiology In Press.

19. Ludwig J, Sanbonmatsu L, Gennetian L, Adam E, Duncan GJ, Katz LF, Kessler RC, Kling JR, Lindau ST, Whitaker RC, McDade TW. Neighborhoods, obesity, and diabetes--a randomized social experiment. $N$ Engl J Med 2011;365(16):1509-19.

20. Powell-Wiley TM, Cooper-McCann R, Ayers CR, Berrigan D, Lian M, McClurkin M, Ballard-Barbash R, Hoehner CM, Leonard T. Change in Neighborhood Socioeconomic Status and Weight Gain: Dallas Heart Study. . American journal of preventive medicine 2015; In Press.

21. Citro CF, Kalton G. Using the American Community Survey:: Benefits and Challenges National Academies Press, 2007.

22. Frank LD, Saelens BE, Powell KE, Chapman JE. Stepping towards causation: do built environments or neighborhood and travel preferences explain physical activity, driving, and obesity? Social science \& medicine 2007;65(9):1898-1914.

23. Foster S, Giles-Corti B. The built environment, neighborhood crime and constrained physical activity: an exploration of inconsistent findings. Preventive medicine 2008;47(3):241-251.

24. Victor RG, Haley RW, Willett DL, Peshock RM, Vaeth PC, Leonard D, Basit M, Cooper RS, Iannacchione VG, Visscher WA, Staab JM, Hobbs HH. The Dallas Heart Study: a population-based probability sample for the multidisciplinary study of ethnic differences in cardiovascular health. Am J Cardiol 2004;93(12):1473-80.

25. Diez Roux AV, Evenson KR, McGinn AP, Brown DG, Moore L, Brines S, Jacobs DR, Jr. Availability of recreational resources and physical activity in adults. Am J Public Health 2007;97(3):493-9.

26. LaMonte MJ, Durstine JL, Addy CL, Irwin ML, Ainsworth BE. Physical activity, physical fitness, and Framingham 10-year risk score: the cross-cultural activity participation study. J Cardiopulm Rehabil 2001;21(2):63-70.

27. Mathieu RAt, Powell-Wiley TM, Ayers CR, McGuire DK, Khera A, Das SR, Lakoski SG. Physical activity participation, health perceptions, and cardiovascular disease mortality in a multiethnic population: the Dallas Heart Study. American heart journal 2012;163(6):1037-40.

28. Sampson RJ, Raudenbush SW, Earls F. Neighborhoods and violent crime: a multilevel study of collective efficacy. Science 1997;277(5328):918-24.

29. Bajari P, Fruehwirth JC, Kim KI, Timmins C. A rational expectations approach to hedonic price regressions with time-varying unobserved product attributes: The price of pollution. The American Economic Review 2012;102(5):1898-1926. 
30. Brookshire DS, Thayer MA, Schulze WD, d'Arge RC. Valuing Public Goods: A Comparison of Survey and Hedonic Approaches. The American Economic Review 1982;72(1):165-177.

31. Can A. Specification and estimation of hedonic housing price models. Regional Science and Urban Economics 1992;22(3):453-474.

32. Rosen S. Hedonic Prices and Implicit Markets: Product Differentiation in Pure Competition. Journal of Political Economy 1974;82(1):34-55.

33. Lancaster KJ. A new approach to consumer theory. The journal of political economy 1966:132-157.

34. Dallas Central Appraisal District. DCAD Data Products. http://www.dallascad.org/DataProducts.aspx Accessed June 1, 2015, 2015.

35. Craig P, Cooper C, Gunnell D, Haw S, Lawson K, Macintyre S, Ogilvie D, Petticrew M, Reeves B, Sutton M. Using natural experiments to evaluate population health interventions: new Medical Research Council guidance. Journal of epidemiology and community health 2012:jech-2011-200375.

36. Galster GC. Homeowners and neighborhood reinvestment Duke University Press, 1987.

37. Heckman JJ. Sample selection bias as a specification error. Econometrica: Journal of the econometric society 1979:153-161.

38. d'Agostino RB. Tutorial in biostatistics: propensity score methods for bias reduction in the comparison of a treatment to a non-randomized control group. Stat Med 1998;17(19):2265-2281.

39. Austin PC. An introduction to propensity score methods for reducing the effects of confounding in observational studies. Multivariate behavioral research 2011;46(3):399-424.

40. Chow GC. Tests of equality between sets of coefficients in two linear regressions. Econometrica: Journal of the Econometric Society 1960:591-605.

41. Rose G. The strategy of preventive medicine. The strategy of preventive medicine. 1992.

42. Cromley EK, McLafferty SL. GIS and public health Guilford Press, 2011.

43. Powell-Wiley TM, Ayers CR, de Lemos JA, Lakoski SG, Vega GL, Grundy S, Das SR, Banks-Richard K, Albert MA. Relationship between perceptions about neighborhood environment and prevalent obesity: data from the Dallas Heart Study. Obesity 2013;21(1):E14-21.

44. Coffee NT, Lockwood T, Hugo G, Paquet C, Howard NJ, Daniel M. Relative residential property value as a socio-economic status indicator for health research. International journal of health geographics 2013;12(1):22.

45. Drewnowski A, Aggarwal A, Rehm CD, Cohen-Cline H, Hurvitz PM, Moudon AV. Environments perceived as obesogenic have lower residential property values. American journal of preventive medicine 2014;47(3):260-274.

46. Rehm CD, Moudon AV, Hurvitz PM, Drewnowski A. Residential property values are associated with obesity among women in King County, WA, USA. Social Science \& Medicine 2012.

47. Vernez Moudon A, Cook AJ, Ulmer J, Hurvitz PM, Drewnowski A. A neighborhood wealth metric for use in health studies. American journal of preventive medicine 2011;41(1):88-97. 
48. Burdette HL, Wadden TA, Whitaker RC. Neighborhood safety, collective efficacy, and obesity in women with young children. Obesity 2006;14(3):518-525.

49. Casagrande SS, Gittelsohn J, Zonderman AB, Evans MK, Gary-Webb TL. Association of walkability with obesity in Baltimore City, Maryland. American journal of public health 2011;101(S1):S318-S324.

50. Hoehner CM, Barlow CE, Allen P, Schootman M. Commuting distance, cardiorespiratory fitness, and metabolic risk. American journal of preventive medicine 2012;42(6):571-578.

51. Hoehner CM, Handy SL, Yan Y, Blair SN, Berrigan D. Association between neighborhood walkability, cardiorespiratory fitness and body-mass index. Social science \& medicine 2011;73(12):1707-1716.

52. Christakis NA, Fowler JH. The spread of obesity in a large social network over 32 years. New England journal of medicine 2007;357(4):370-379.

53. Cohen-Cole E, Fletcher JM. Is obesity contagious? Social networks vs. environmental factors in the obesity epidemic. Journal of health economics 2008;27(5):1382-1387.

54. Burdette AM, Hill TD. An examination of processes linking perceived neighborhood disorder and obesity. Social science \& medicine 2008;67(1):38-46.

55. Papas MA, Alberg AJ, Ewing R, Helzlsouer KJ, Gary TL, Klassen AC. The built environment and obesity. Epidemiologic reviews 2007;29(1):129-143.

56. Leonard T, Zhang L, Hoehner C. Variation in Park Facility Valuations across Neighborhoods. Working Paper 2013.

57. Seo W, von Rabenau B. Spatial Impacts of Microneighborhood Physical Disorder on Property Resale Values in Columbus, Ohio. Journal of Urban Planning and Development 2010;137(3):337-345.

58. Harris DR. " Property Values Drop When Blacks Move in, Because...": Racial and Socioeconomic Determinants of Neighborhood Desirability. American sociological review 1999:461-479.

59. Leonard T, Murdoch J. The neighborhood effects of foreclosure. Journal of Geographical Systems 2009;11(4):317-332-332.

60. Zhang L, Leonard T. Neighborhood impact of foreclosure: A quantile regression approach. Regional Science and Urban Economics 2014;48:133--143.

61. Zhang L, Leonard T, Murdoch JC. Time and Distance Heterogeneity in the Neighborhood Spillover Effects of Foreclosed Properties. Housing Studies 2015; In Press.

62. Oakley D. Locational Patterns of Low-Income Housing Tax Credit Developments A Sociospatial Analysis of Four Metropolitan Areas. Urban Affairs Review 2008;43(5):599-628.

63. Oakley D, Burchfield K. OUT OF THE PROJECTS, STILL IN THE HOOD: THE SPATIAL CONSTRAINTS ON PUBLIC - HOUSING RESIDENTS'RELOCATION IN CHICAGO. Journal of Urban Affairs 2009;31(5):589-614.

64. Schill MH, Wachter SM. The spatial bias of federal housing law and policy: Concentrated poverty in urban America. University of Pennsylvania Law Review 1995:1285-1342.

65. Wang X, Varady DP. Using hot-spot analysis to study the clustering of section 8 housing voucher families. Housing Studies 2005;20(1):29-48. 
66. Housing and Urban Development (HUD). HUD Payment Standards. 2015.

67. Leonard T, Jha N, Zhang L. Neighborhood Price Externalities of Foreclosure Rehabilitation: An Examination of the Neighborhood Stabilization Program. Empirical Economics In Press. 


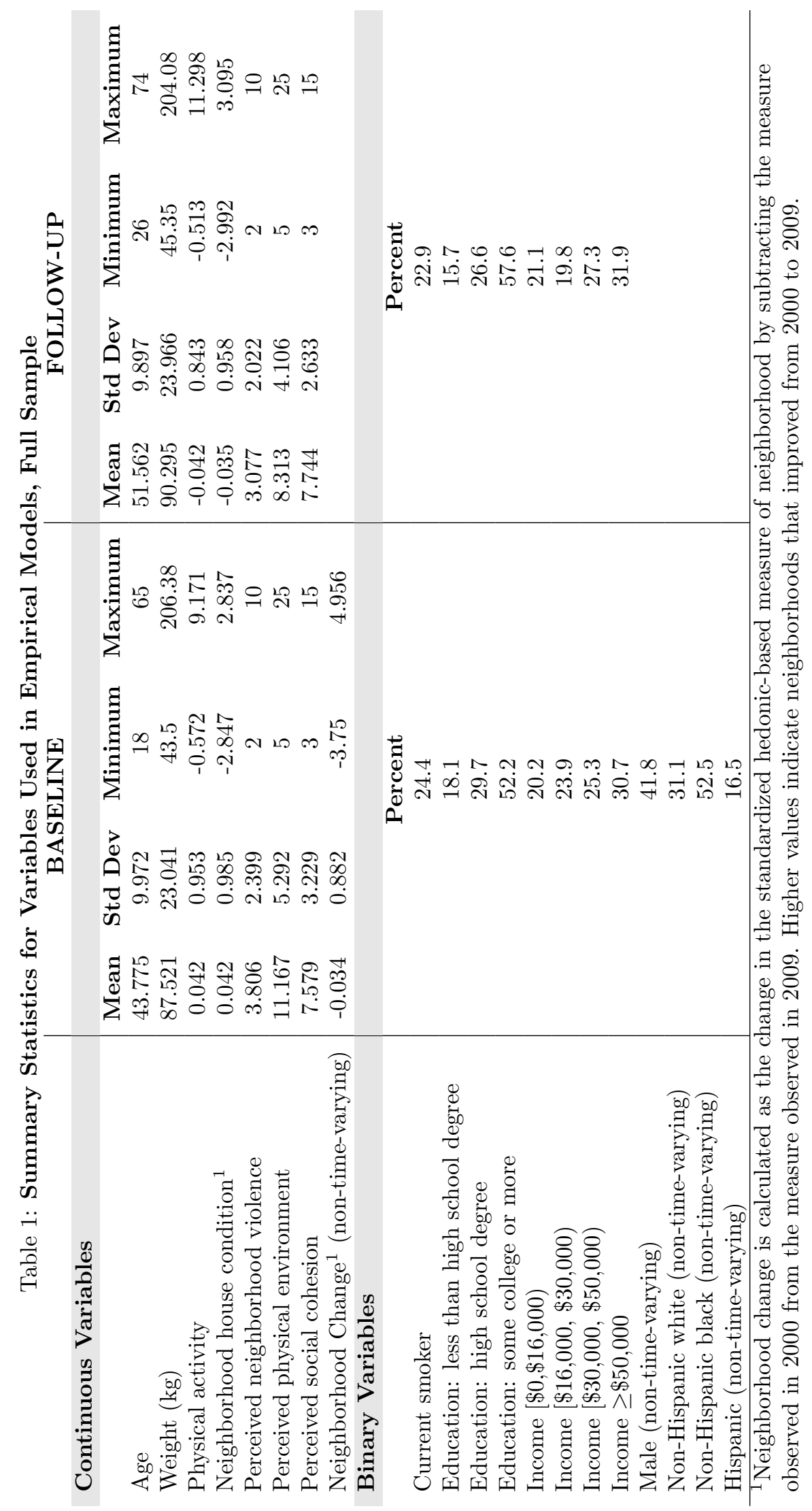




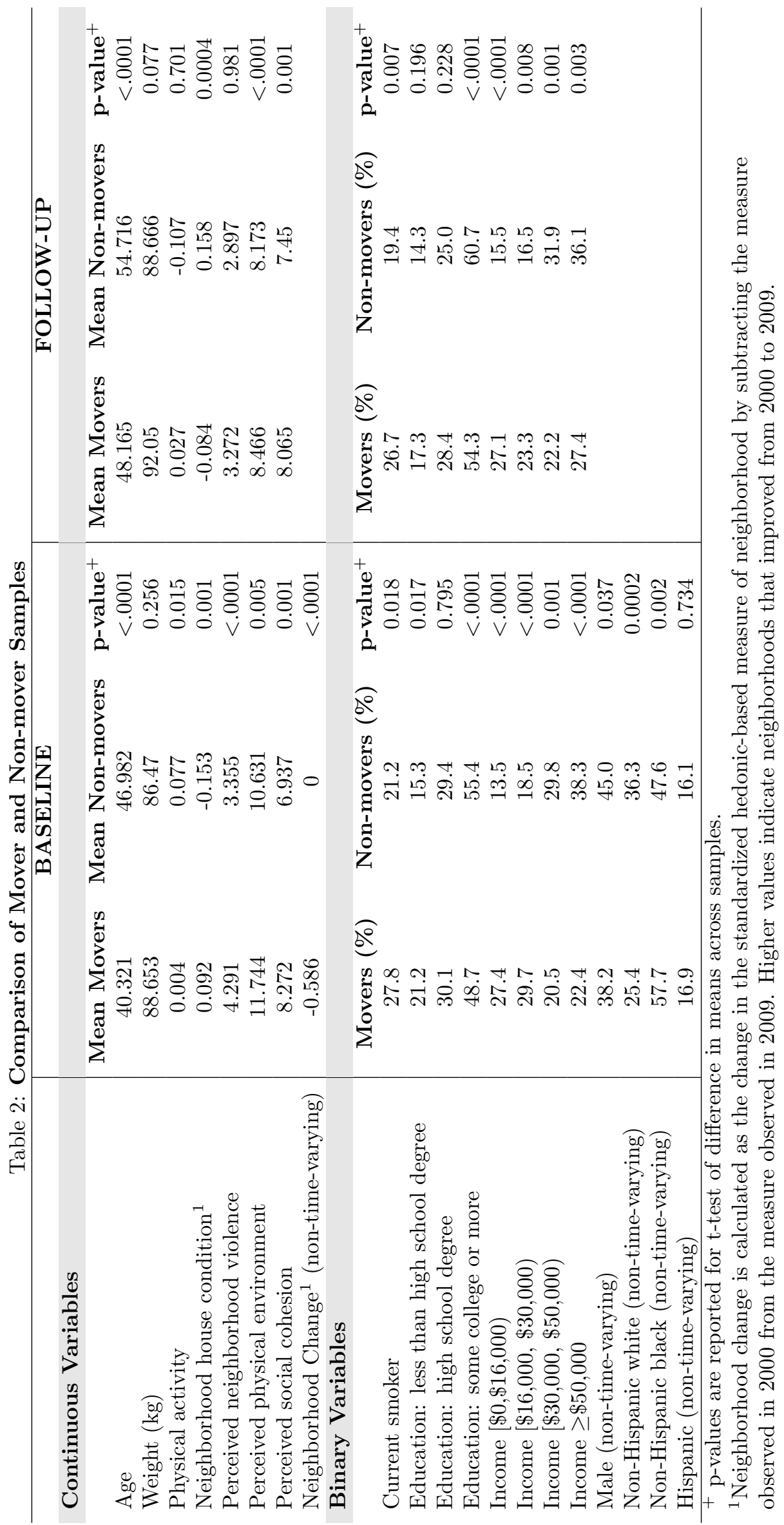


Table 3: Coefficient Estimates for Difference-in-Difference Models Relating Change in Neighborhood Condition to Weight Gain, Full Sample ( $N=1253)$

\begin{tabular}{|c|c|c|c|}
\hline & Model 1 & Model 2 & Model 3 \\
\hline \multirow[t]{2}{*}{ FOLLOW-UP } & $1.741^{* *}$ & $1.757^{* *}$ & $1.729^{*}$ \\
\hline & $(0.502)$ & $(0.501)$ & $(0.539)$ \\
\hline \multirow[t]{2}{*}{ Neighborhood change } & 0.669 & 0.727 & 0.833 \\
\hline & $(0.806)$ & $(0.801)$ & $(0.803)$ \\
\hline \multirow[t]{2}{*}{ Neighborhood change $\times$ FOLLOW-UP } & -0.572 & $-0.651^{+}$ & $-0.664^{+}$ \\
\hline & $(0.326)$ & $(0.337)$ & $(0.353)$ \\
\hline \multirow[t]{2}{*}{ Age } & $1.248^{* * *}$ & $1.237^{* * *}$ & $1.24^{* * *}$ \\
\hline & $(0.17)$ & $(0.17)$ & $(0.171)$ \\
\hline \multirow[t]{2}{*}{$\mathrm{Age}^{2}$} & $-0.012^{* * *}$ & $-0.012^{* * *}$ & $-0.012^{* * *}$ \\
\hline & $(0.002)$ & $(0.002)$ & $(0.002)$ \\
\hline \multirow[t]{2}{*}{ Height } & $1.027 * * *$ & $1.024^{* * *}$ & $1.035^{* * *}$ \\
\hline & $(0.096)$ & $(0.096)$ & $(0.097)$ \\
\hline \multirow[t]{2}{*}{ Male } & -3.077 & -3.012 & -3.143 \\
\hline & $(1.755)$ & $(1.755)$ & $(1.768)$ \\
\hline \multirow[t]{2}{*}{ Non-Hispanic black } & $8.2^{* * *}$ & $8.452^{* * *}$ & $8.488^{* * *}$ \\
\hline & $(1.39)$ & $(1.404)$ & $(1.415)$ \\
\hline \multirow[t]{2}{*}{ Hispanic } & 2.936 & 3.006 & 2.853 \\
\hline & $(1.881)$ & $(1.877)$ & $(1.927)$ \\
\hline \multirow[t]{2}{*}{ Current smoker } & $-4.991 * * *$ & $-4.959 * * *$ & $-5.307 * * *$ \\
\hline & $(1.034)$ & $(1.035)$ & $(1.011)$ \\
\hline \multirow[t]{2}{*}{ Income $[\$ 0, \$ 16,000)$} & -1.227 & -1.198 & -1.003 \\
\hline & $(0.809)$ & $(0.802)$ & $(0.789)$ \\
\hline \multirow[t]{2}{*}{ Income $[\$ 16,000, \$ 30,000)$} & 0.421 & 0.465 & 0.573 \\
\hline & $(0.715)$ & $(0.712)$ & $(0.707)$ \\
\hline \multirow[t]{2}{*}{ Income $[\$ 30,000, \$ 50,000)$} & $1.545^{*}$ & $1.57^{*}$ & $1.634^{*}$ \\
\hline & $(0.589)$ & $(0.589)$ & $(0.599)$ \\
\hline \multirow[t]{2}{*}{ Education: less than high school degree } & 1.286 & 1.335 & 1.244 \\
\hline & $(1.204)$ & $(1.212)$ & $(1.184)$ \\
\hline \multirow[t]{2}{*}{ Education: high school degree } & 0.429 & 0.436 & 0.532 \\
\hline & $(0.706)$ & $(0.706)$ & $(0.728)$ \\
\hline \multirow[t]{2}{*}{ Physical activity } & $-0.927 * * *$ & $-0.941^{* * *}$ & $-0.947 * * *$ \\
\hline & $(0.24)$ & $(0.241)$ & $(0.248)$ \\
\hline \multirow[t]{2}{*}{ Mover } & $3.217^{*}$ & $3.194^{*}$ & $3.29 *$ \\
\hline & $(1.308)$ & $(1.306)$ & $(1.309)$ \\
\hline \multirow[t]{2}{*}{ Neighborhood house condition } & & 0.32 & 0.255 \\
\hline & & $(0.285)$ & $(0.292)$ \\
\hline \multirow[t]{2}{*}{ Perceived neighborhood violence } & & & -0.178 \\
\hline & & & $(0.112)$ \\
\hline \multirow[t]{2}{*}{ Perceived neighborhood physical environment } & & & 0.008 \\
\hline & & & $(0.055)$ \\
\hline \multirow[t]{2}{*}{ Perceived neighborhood social cohesion } & & & 0.11 \\
\hline & & & $(0.087)$ \\
\hline \multirow[t]{2}{*}{ Heckman correction } & -16.735 & -17.584 & -18.205 \\
\hline & $(6.332)$ & $(6.36)$ & $(6.368)$ \\
\hline \multirow[t]{2}{*}{ Constant } & -118.46 & -117.82 & -119.55 \\
\hline & $(17.667)$ & $(17.647)$ & $(17.762)$ \\
\hline
\end{tabular}

The dependent variable for all models is kilograms of weight.

Robust standard errors 3 re given in parenthesis.

*** $\mathrm{p}<0.001, * * \mathrm{p}<0.01,{ }^{*} \mathrm{p}<0.05,+\mathrm{p}<0.10$ 
Table 4: Movers vs Non-movers: Coefficient Estimates for Difference-in-Difference Models Relating Change in Neighborhood Condition to Weight Gain

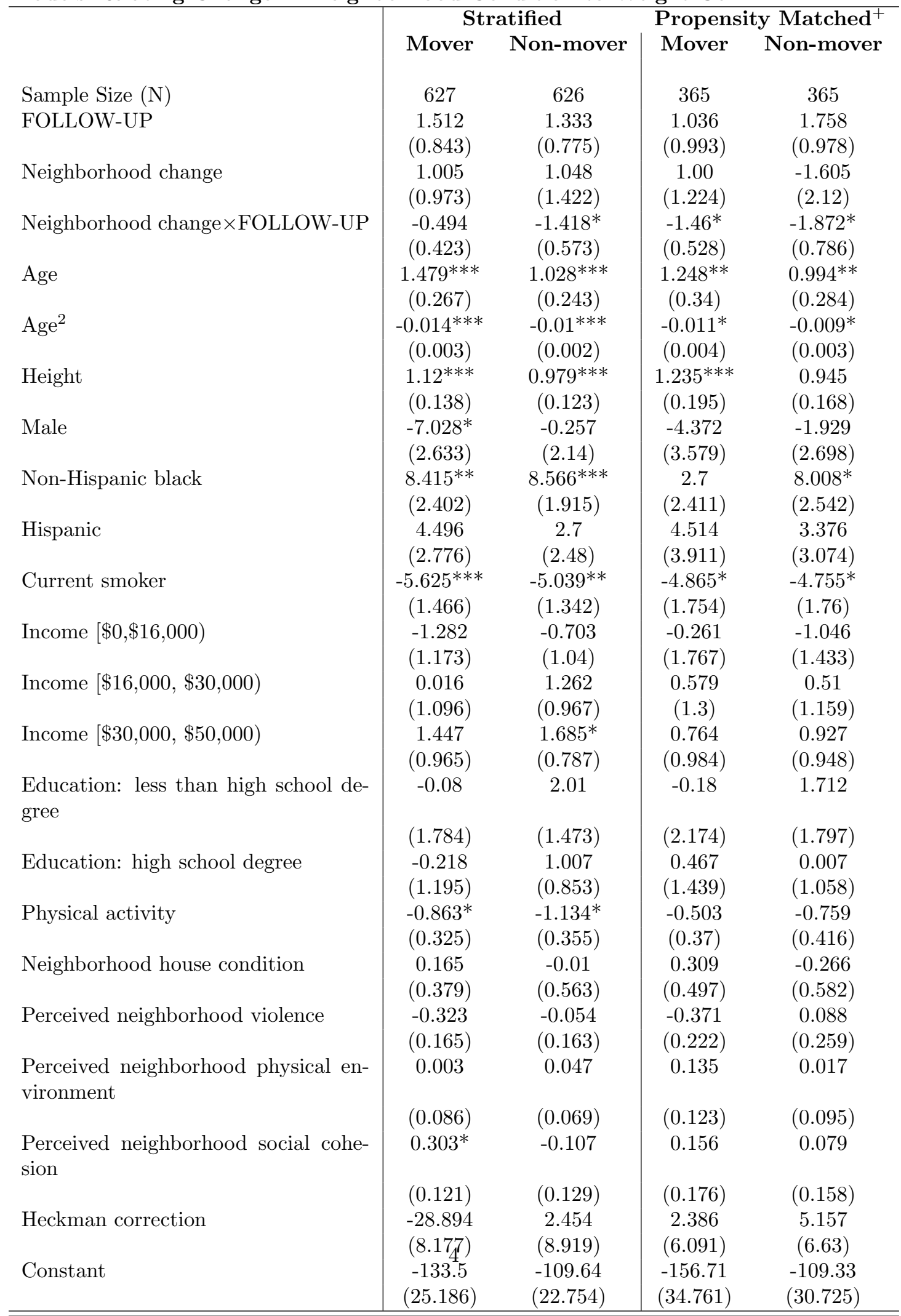

The dependent variable for all models is kilograms of weight. Robust standard errors are given in parenthesis.

*** $\mathrm{p}<0.001,{ }^{* *} \mathrm{p}<0.01,{ }^{*} \mathrm{p}<0.05,+\mathrm{p}<0.10$

+ Liklihood of moving was matched based on a \pm .05 criteria. 